\title{
Correction to: ChIP-seq and RNA-seq for complex and low-abundance tree buds reveal chromatin and expression co-dynamics during sweet cherry bud dormancy
}

Noémie Vimont ${ }^{1,2} \cdot$ Fu Xiang Quah ${ }^{2}$ - David Guillaume-Schöpfer ${ }^{2}$ - François Roudier ${ }^{3}$. Elisabeth Dirlewanger ${ }^{1}$. Philip A. Wigge ${ }^{2} \cdot$ Bénédicte Wenden $^{1} \cdot$ Sandra Cortijo $^{2}$ (D)

Published online: 20 November 2020

(C) Springer-Verlag GmbH Germany, part of Springer Nature 2020

Correction to: Tree Genetics \& Genomes (2020) 16:9

https://doi.org/10.1007/s11295-019-1395-9

The correct name of the 3 rd Author is presented in this paper.

Publisher's note Springer Nature remains neutral with regard to jurisdictional claims in published maps and institutional affiliations.

The online version of the original article can be found at https://doi.org/ 10.1007/s11295-019-1395-9

Sandra Cortijo

Sandra.cortijo@slcu.cam.ac.uk

1 UMR 1332 BFP, INRA, University Bordeaux, F-33140 Villenave d'Ornon, F-33140 Bordeaux, France

2 The Sainsbury Laboratory, University of Cambridge, Cambridge CB2 1LR, UK

3 Laboratoire Reproduction et Développement des Plantes, University Lyon, ENS de Lyon, UCB Lyon 1, CNRS, INRA,

F-69342 Lyon, France 